\title{
Gender Inequality in the Performance of Bricklaying and Blocklaying Practical Skills among Technical College Students in Niger State, Nigeria
}

\author{
Ibrahim, D., Adisa, S., Abdulkadir, M \& Nene, H. \\ Industrial and Technology Education Department, Federal University of Technology Minna \\ Library and Information Technology Department, Federal University of Technology Minna
}

\begin{abstract}
This study was designed to determine the gender difference in the performance of Bricklaying and Blocklaying practical skills among the National Technical Certificate (NTC) III Boys and Girls in Niger state. Three research questions and three hypotheses guided the study. An experimental research design was employed for the study. The study was carried out in Government Technical College Minna, Federal Science and Technical College, Shiroro, Government Technical College Kontagora and Suleiman Barau Technical College, Suleja. A total of 24 respondents comprising 12 female and 12 male students were used as population of the study. A developed instrument for assessing student manipulative skills in bricklaying and blocklaying practices (IASMSBBP) at technical colleges' level was used for data collection. The reliability coefficient of the instrument was 0.88 and could therefore serve as a comprehensive instrument for determining the gender difference in the performance of Bricklaying and Blocklaying practical skills among NTC III Boys and Girls students. Cronbach Alpha, Mean and Standard Deviation were used as the statistical tools to analyze the data, while $t$ - test statistic was employed to test the three null hypotheses of the study at 0.05 level of significance. The findings of the study revealed that the male students performed better in bonding task (Flemish bond,) arch construction and construction of fire place and chimney stack task than the female students. It was recommended that Teachers should ensure effective teaching and learning and acquisition of practical skills in bricklaying and blocklaying among the male and female students in order to generate in them the much desired motivation in building technology and thereby increase their aptitude, interest, attitude and ultimately achievement in their practical skills and Females students should work conscientiously to achieve equity for males and free themselves from stereotyping roles.
\end{abstract}

\section{Introduction}

Technical and Vocational Education can be described as series of controlled and organized experiences arranged to prepare a person for socially useful employment. Okoro (1999) sees vocational education as a term that is all-embracing than technical education. According to Okoro, vocational education is a post-secondary training programme whose major purpose is the production of technicians. The National Policy on Education (FRN 2004) defines 'Technical education in a comprehensive term referring to those aspects of the educational process involving, in addition to general education, the study of technologies and related sciences and the acquisition of practical skills, attitudes, understanding and knowledge relating to occupations in various sectors of economic and social life.

The goals of technical and vocational education are to provide trained manpower in the applied sciences, technology and business particularly at the craft, advanced craft and technical level. It is also to provide technical knowledge and vocational skills necessary for agriculture, commercial and economic development and to impart the necessary skills into individuals in order to make them self-reliant economically. In pursuance of these goals; Science and Technology Education act (2000) declared that, "it is the policy of the federal Government of Nigeria to encourage men and women equally, of all ethnic, racial, and economic background to acquire skills in science, technology and mathematics and to have equal opportunity in education, training and employment in scientific and technology fields and thereby promoting scientific literacy and technology" (S \& E Act, 2000). The expectation is that during laboratory activities, students are provided with experiences predisposing towards acquisition of technical process skills needed for the translation of ideas or instructions into a practical form. Gender and its manifestation in various human activities appear to be a strong predictor of human conduct. In education, many differences have been documented between achievements of males and females (Mark 2007). Macoby and Jackline (1991) feel that gender is a range of characteristics used to distinguish between males and females particularly in the case of men and women and the masculine and feminine attributes attached to them. Gender is the amount of masculinity or femininity found in a person, and obviously, where there are mixtures of both in many humans, the normal male has a preponderance of masculinity and the normal female a preponderance of feminist (Robert, 1968). The World Health Organization 
(WHO 2009), also defined gender as the result of socially constructed ideas about the behavior, actions and roles a particular sex performs.

According to Wall (1997), it is the natural difference between men and women, which dictate on their occupational choice, while Nikolaenko, (2005) who stated that the boys are better at mental manipulation of images which may benefit problem - solving, design and construction skills. Natalie (2006) noted that the gender psychological difference at birth for males and females are the same and that it is the way they are treated that gives them what we consider as typical male and female characteristics. Liebert (1992) \& Okou (1991) concluded that sex has a strong influence on vocational aspirations. Depending on the context, the discriminating characteristics vary from sex to social role to gender identity. In written examination, many differences have been documented between the achievements of males and females but, it has not been established whether the difference in performance between boys and girls in these examinations is greatly due to gender differences in the students' ability to perform Bricklaying and Blocklaying practical work. Depending on where you live, gender inequalities in technology can ranges from slightly too drastically to prevalent situation. Gender relating issues are present in work places and in higher education institutions. "All students of both gender need to acquire the skills necessary to become consumers capable of critically assessing the technologies they use, resulting in the ability to make more informed decisions

Yanger, Engen \& Snifer (1999) suggested that the laboratory can provide an excellent opportunity for the teaching of technical skills. They found that students in "discussion" setting were able to learn some laboratoryoriented intellectual skills as efficiently as students in laboratory setting but they were unable to perform competently on a range of technical skills.

Nabulya (2004) also found out that more males than females chose vocational and technical subjects. Johnson and Murphy (1997) also reported that in Britain, girls perform consistently better than boys in observational skills while boys performed consistently better in measurement skills and computational skills. But in all process skills, Hobbs, Bolt, Erickson, Noels, \& Siebel, (1979) reported that performance between the two sexes was about the same.

\section{Statements Of The Problem}

In Nigeria, the trend of academic excellence of technical students at ' $\mathrm{O}$ ' level has shown that boys perform better than girls in building construction examination (NABTEB 2003). Building technology being one of the essential technical subjects in most of the professional courses at the university level, experience poor performance by the girls, and thus limit their opportunity to offer professional courses like building, building technology, building construction, civil engineering, structural engineering, architectural engineering and so on. The downward spiral of female enrolment is accompanied by decrease in achievement and interest. Poor performance in building which potentially contributes to lowering girls interest in the subjects reduces the women in technological carriers in Niger State today where we are currently in need of highly skilled human power for national development.

Macoby and Jackline (1991), show that gender differences in attainment were established in areas of mathematics, spatial and verbal abilities with boys excelling in the first two and girls in the later. Also, a number of studies have been done on issues about gender differences and performance in core science subjects like biology, chemistry and physics where females perform better in the first two subjects and males in the last. Evidence have not been established whether there is a gender difference between boys and girls in bricklaying and blocklaying practical skills at technical colleges of Niger State, Nigeria. Based on the foregoing, therefore, the study seek to determine the gender differences in the performance of bricklaying and blocklaying practical skills among the students in technical colleges in Niger State, Nigeria.

\section{Purpose Of The Study}

The study determines whether there are differences in the performance of bricklaying and blocklaying practical skill among boys and girls in technical colleges in Niger State. Specifically, the study seeks to determine

1. Gender differences in the ability of the male and female students to perform the brick/ block bonding (Flemish bond) practical task.

2. Gender differences in the ability of the male and female students in arch construction practical task.

3. Gender differences in the ability of the male and female students to construct fire place and chimney stack practical skill.

\section{Research Questions}

The following research questions guided the study:

- What are the gender differences in the ability of the male and female students to perform the brick/ block bonding (Flemish bond) practical task? 
- What are the gender differences in the ability of the male and female students in arch construction practical task?

- What are the gender differences in the ability of the male and female students to construct fire place and chimney stack practical task?

\section{Hypothesis Of The Study}

Ho i. There is no significant difference between male and female students in performing the brick/block bonding (Flemish bond) practical task.

Ho ii. There is no significant difference between male and female students in the arch construction practical task.

Ho iii. There is no significant difference between male and female students in the construction of fire place and chimney stack practical task.

\section{Methodology}

An experimental research design was adopted for the study. This involve the assessment or observation of the differences in manipulative skills of bricklaying and blocklaying practice between males and females student in four different mixed technical colleges in Niger state. A developed assessment instrument (IASMSBBP) was used for assessing students' manipulative skills in bricklaying and blocklaying practice at technical college level in Niger state, Nigeria. Three tasks were administered to the students (male and female) independently at the selected schools using the assessment instrument to record their scores and compared to determine if there was any significant difference in the performance between them.

\section{Research Question 1}

What are the gender differences in the ability of the male and female students to perform the brick/ block bonding (Flemish bond) practical task?

In determining the gender difference of male and female students of bricklaying and blocklaying practice at Government Technical College, Minna, Federal Science and Technical College, Shiroro, Government Technical College, Kontagora and Suleiman Barau Technical College, Suleja, a practical task (Flemish bond) was given to the students to demonstrate their abilities while the students were assessed. The result of the assessment is presented in the tables 1 below:

TABLE 1:

Mean Scores of Students on Brick/Block Bonding (Flemish bond type) Practical task.

\begin{tabular}{lcccc}
\hline Gender & Number of students & Scores & \\
& & & \\
& & & \\
\hline Male & 12 & $72,73,72,79,80,82,73,80,58,80,79 \& 82$ & 75.00 & 6.61 \\
Female & 12 & $61,62,70,72,70,75,82,75,73,80,73 \& 70$ & 72.75 & 9.68 \\
\hline
\end{tabular}

The data presented in Table 1 reveals that the male students have mean score of 75.00 and standard deviation of 6.61 while the female students have mean score of 72.75 and standard deviation 9.68 . This signifies that the male students performed better in bonding task (Flemish bond) than the female students.

\section{RESEARCH QUESTION 2}

What are the gender differences between male and female students in arch construction practical task?

In determining the gender difference of male and female students of bricklaying and blocklaying practice at Government Technical College, Minna, Federal Science and Technical College, Shiroro, Government Technical College, Kontagora and Suleiman Barau Technical College, Suleja, a practical task (Arch construction) was given to the students to demonstrate their abilities while the students were assessed. The result of the assessment is presented in tables 2 below:

TABLE 2:

Mean Scores of Students on arch Construction Practical task.

\begin{tabular}{|c|c|c|c|c|}
\hline Gender & Number of students & Scores & Mean & $\mathrm{SD}$ \\
\hline Male & 12 & $62,69,59,64,71,58,52,6163,67,50 \& 53$ & 60.75 & 6.69 \\
\hline Female & 12 & $75,60,61,52,62,61,60,51,51,61,60 \& 45$ & 58.25 & 7.42 \\
\hline
\end{tabular}


The data presented in Table 2 indicated that male students have mean score of 60.75 and standard deviation of 6.69 while female students have mean score of 58.25 and standard deviation of 7.42. This reveals that the male students performed better than the female students in the arch construction practical task.

\section{RESEARCH QUESTION 3}

What are the gender differences between male and female students in the construction of fire place and chimney stack practical task?

In determining the gender difference of male and female students of bricklaying and blocklaying practice at Government Technical College, Minna, Federal Science and Technical College, Shiroro, Government Technical College, Kontagora and Suleiman Barau Technical College, Suleja, a practical task, (Fire place and chimney stack) construction was given out to the students to demonstrate their abilities while the students were assessed. The result of the assessment is presented in tables 3 below:

TABLE 3:

Mean Scores of Students on the Construction of fire Place \& Chimney Stack Practical task.

\begin{tabular}{|c|c|c|c|c|}
\hline Gender & Number of students & Scores & Mean & $\mathrm{SD}$ \\
\hline Male & 12 & $63,68,57,72,68,62,62,71,69,57,62 \& 68$ & 64.92 & 5.01 \\
\hline Female & 12 & $58,60,56,65,64,67,66,61,67,64,59 \& 52$ & 61.58 & 4.74 \\
\hline
\end{tabular}

The data presented in Table 3 shows that, the male students have mean score of 64.92 and standard deviation of 5.01 while the female students have mean score of 61.58 and standard deviation 4.74. This signifies that the male students performed better than the female students in the construction of fire place and chimney stack practical task.

\section{HYPOTHESIS TESTING}

Hypothesis 1

There is no significant difference in the mean performance scores between the male and female students in brick/block bonding (Flemish bond) practical task.

TABLE 4:

$t$ - test Analysis of the Students in the Performance of Brick/Block Bonding Practical task.

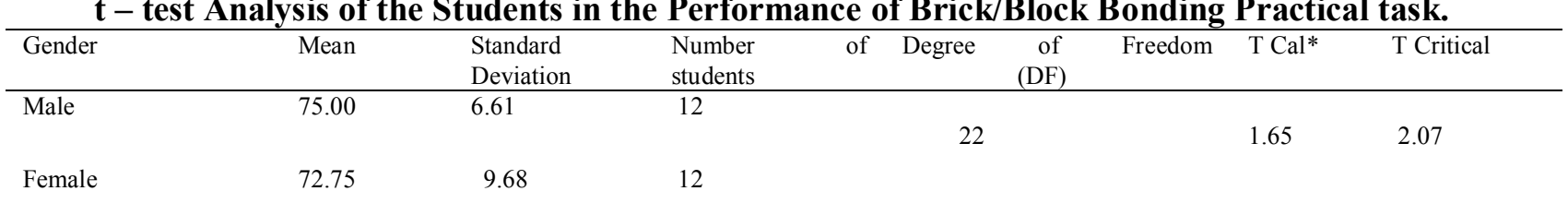

\section{*Not Significant}

Table 4 indicates that the calculated value of t-test is 1.65 . This value is less than the critical t-value found to be \pm 2.07 of $22 \mathrm{df}$ at 0.05 level of significance. Consequently, the null hypothesis was accepted since the calculated value of $t$ is less than the critical $t$-value. This implies that there is statistically no significant difference in the mean performance scores of the male and female students in the brick/block bonding (Flemish bond) practical task.

Hypothesis 2

There is no significant difference in the mean performance scores between the male and female students in arch construction practical task.

TABLE 5:

$t$ - test Analysis of the Students in the Performance of arch Construction Practical task.

\begin{tabular}{|c|c|c|c|c|c|c|c|c|}
\hline Gender & Mean & Standard Deviation & Number of students & Degree & $\begin{array}{c}\text { of } \\
\text { (DF) }\end{array}$ & Freedom & T Cal* & T Critical \\
\hline Male & 60.75 & 6.69 & 12 & & & & & \\
\hline Female & 58.25 & 7.42 & 12 & 22 & & & 2.13 & 2.07 \\
\hline
\end{tabular}

\section{*Significant}


Table 5 indicates that the calculated value of t-test is 2.13 . This value is greater than the critical $t$ value found to be \pm 2.07 of $22 \mathrm{df}$ at the significant level of 0.05 . Consequently, the null hypothesis was rejected since the calculated value of $t$ is greater than the critical $t$-value. This implies that there is significant difference in the mean performance scores of the male and female students in the arch construction practical task. Hypothesis 3

There is no significant difference in the mean performance scores between the male and female students in construction of fire place and chimney stack practical task.

TABLE 6:

$t$ - test Analysis of the Students in the Performance of fire Place and Chimney Stack Construction Practical task.

\begin{tabular}{lllcccccc}
\hline Gender & Mean & Standard Deviation & $\begin{array}{l}\text { Number } \\
\text { students }\end{array}$ & of Degree & $\begin{array}{c}\text { of } \\
\text { (DF) }\end{array}$ & Freedom & T Cal* & T Critical \\
\hline Male & 64.92 & 5.05 & 12 & 22 & & & 4.07 & 2.07 \\
Female & 61.58 & 4.74 & 12 & & & &
\end{tabular}

\section{*Significant}

Table 6 indicates that the calculated value $t$-test is 4.07 . This value is greater than the critical $t$ value found to be \pm 2.07 of $22 \mathrm{df}$ at the significant level of 0.05 . Consequently, the null hypothesis was rejected since the calculated value of $t$ is greater than the critical $t$-value. This implies that there is significant difference in the mean performance scores of the male and female students in construction of fire place and chimney stack practical task.

\section{Discussion Of Findings}

Based on the data collected, it was found out that, the boys demonstrated more competency and proficient performance and show a thorough and effective application of knowledge and skills that meet the standard in blocklaying and bricklaying practice than the female. This finding was in line with the view of Nikolaenko, (2005) who stated that the boys are better at mental manipulation of images which may benefit problem - solving, design and construction skills.

Finding regarding to research question 1 shows that, the female students performed equally well as the male students in the construction brick/block bonding (Flemish bond) practical task. This finding was in line with the views of Natalie (2006) who noted that the gender psychological difference at birth for males and females are the same and that it is the way they are treated that gives them what we consider as typical male and female characteristics. Supporting the view of Natalie, Johnson and Murphy (2007) reported that in Britain, girls perform consistently better than boys in observational skills while boys performed consistently better in measurement skills and computational skills. This positive change could be related to environmental factor, parental influence, the way and manner an individual was brought up, readiness to learn or interest and so on. But in all process skills, Hobbs, Bolt, Erickson, Noels, \& Siebel, (1979) reported that performance between the two sexes was about the same.

\section{Conclusion}

The practical task used to determine gender inequality in the performance of Bricklaying and Blocklaying Practical skills among technical college students (Male and Female) in Niger State, Nigeria were appropriate for the study. Also the instrument used for assessing the entire practical task was appropriate. However, one of the factors responsible for the gender inequality at technical colleges may be attributed to the practical task. Furthermore students' learn better where practical task areas are being revealed to them. It is concluded that when the findings of this study are effectively implemented, the significant gender differences between male and female students in bricklaying and blocklaying practical task will be reduced to minimum.

\section{Recomendation}

Base on the findings of the study, it was recommended that;

- Government, Teachers and school counselors should explore avenues, strategies and best practices in bricklaying and blocklaying manipulative skill towards improving students' commitment to building technology.

- Teachers should ensure effective teaching and learning and acquisition of practical skills in bricklaying and blocklaying among the male and female students in order to generate in them the much desired motivation in building technology and thereby increase their aptitude, interest, attitude and ultimately achievement in their practical skills. 
- Females should work conscientiously to achieve equity for females and free themselves from stereotyping roles.

- More females should be enrolled in building technology through proper awareness and orientation by government and the parents.

- The students should devote more time to technical activities, discourse and take optimal advantage of the teaching-learning situation.

\section{References}

[1]. O. M, Okoro, Principles and Methods of Vocational and teachers Education (Nsukka: University Trust Publishers, 1999)

[2]. Federal Republic of Nigeria (FRN), National Policy on Education Lagos, Federal Ministry of Education 7-50.(NERDC Publisher Lagos 2004)

[3]. Science \& Education Acts (S \& E Acts) Equal Opportunity Act: (Federal Republic of Nigeria, Lagos, 2000) J. A, Mark, Educational research: Quantitative, qualitative and mixed approaches (3rd Ed.). Thousand Oaks, CA: Sage. Mathematics Journal of Education and Technology 1(1), 2007, $161-168$

[4]. E. E. Maccoby and C.N Jacklin, the Psychology of Sex Differences. (Stanford, California: Stanford University Press, 1991)

[5]. S. Robert, Changes in masculine and feminine traits over time: A meta-analysis. Sex Roles, 36, 1968, 305-325

[6]. World Health Organization (WHO), what do we mean by "sex" and "gender"? Retrieved 2009-09-29 at www.wikipedia.com

[7]. M.S. Wall, Occupational Self-Selection: A Human Capital Approach to Sex Differences in Occupational Structure, the Review of Economics and Statistics, 63, 1997, 60- 69.

[8]. J. Nikolaenko, (2005). 'Brain Development, XI: Sexual Dimorphism', American Journal of Psychiatry 156

[9]. G. Natalie, Managing gender difference issues in the D \& T workshop: a Research Project Undertaken as part of a Gatsby Fellowship Relating to a Master's Degree Research Study. MA, 2006

[10]. V.C. Liebert, Male, Female, and the Higher Learning: The Educational Significance of Differences between the Sexes, Journal of Higher Education, 30, 1992, 67-72.

[11]. J. A. Okou, Gender and Academic Specialties: Trends among Recipients of College Degrees in the 1980s, Sociology of Education, 68, 1991, 81-98.

[12]. M. Yanger, E. Eigen \& J. Snifer, the Gender Gap and Classroom Interactions: Reality and Rhetoric? British Journal of Sociology of Education, 20(2), 1999, 325-341

[13]. A. E. Nabulya, Sex Differences in Occupational Selection: The Choice of College Majors, Review of Economics and Statistics, 66, 2004, 157-163.

[14]. M. S. Johnson, and B. M. Murphy, Sex Differences in Performance on the Mathematics Section of the Scholastic Aptitude Test: A Bidirectional Validity Study, Harvard Educational Review, 62, 2007, 323-336.

[15]. V.F. Hobbs et'al, Sex Differences in Historical Knowledge and School Grades: A 26 Nation Study, Personalit and Individual Differences 27, 1979, 1221- 1229 